\title{
What patients with pulmonary fibrosis and their partners think: a live, educative survey in the Netherlands and Germany
}

\author{
Mirjam J.G. van Manen ${ }^{1}$, Michael Kreuter ${ }^{2,3}$, Bernt van den Blink \\ Ute Oltmanns ${ }^{2,3}$, Karin Palmowski ${ }^{2,3}$, Eva Brunnemer ${ }^{2,3}$, Simone Hummler ${ }^{2}$, \\ Nelleke C. Tak ${ }^{1}$, Leon van den Toorn ${ }^{1}$, Jelle Miedema ${ }^{1}$, Henk C. Hoogsteden ${ }^{1}$ \\ and Marlies S. Wijsenbeek ${ }^{1}$
} Affiliations: ${ }^{1}$ Dept of Respiratory Medicine, Erasmus University Medical Center, Rotterdam, Netherlands.
${ }^{2}$ Center for Interstitial and Rare Lung Diseases, Pneumology and Respiratory Critical Care Medicine,
Thoraxklinik, University of Heidelberg, Heidelberg, Germany. ${ }^{3}$ Translational Lung Research Center
Heidelberg, Member of the German Center for Lung Research, Heidelberg, Germany.

Correspondence: Marlies Wijsenbeek, Dept of Respiratory Medicine, Erasmus University Medical Center, 's-Gravendijkwal 230, Rotterdam, 3015 CE, The Netherlands. E-mail: m.wijsenbeek-lourensवerasmusmc.nl

ABSTRACT Pulmonary fibrosis greatly impacts patients and their partners. Unmet needs of patients are increasingly acknowledged; the needs of partners often remain unnoticed. Little is known about the best way to educate patients and partners. We investigated pulmonary fibrosis patients' and partners' perspectives and preferences in care, and the differences in these between the Netherlands and Germany. Additionally, we evaluated whether interactive interviewing could be a novel education method in this population.

Patients and partners were interviewed during pulmonary fibrosis patient information meetings. In the Netherlands, voting boxes were used and results were projected directly. In Germany, questionnaires were used.

In the Netherlands, 278 patients and partners participated; in Germany, 51. Many participants experienced anxiety. Almost all experienced misunderstanding, because people do not know what pulmonary fibrosis is. All expressed a need for information, psychological support and care for partners. Use of the interactive voting system was found to be pleasant (70\%) and informative (94\%).

This study improves the knowledge of care needs of patients with pulmonary fibrosis and their partners. There were no major differences between the Netherlands and Germany. Interactive interviewing could be an attractive method to acquire insights into the needs and preferences of patients and partners, while providing them with information at the same time.

@ERSpublications

The needs of patients with pulmonary fibrosis and partners, and the value of interactive interviewing http://ow.ly/M02t307jdEh

Cite this article as: van Manen MJG., Kreuter M, van den Blink B, et al. What patients with pulmonary fibrosis and their partners think: a live, educative survey in the Netherlands and Germany. ERJ Open Res 2017; 3: 00065-2016 [https://doi.org/10.1183/23120541.00065-2016].

This article has supplementary material available from openres.ersjournals.com

Received: June 012016 | Accepted after revision: Nov 222016

Conflict of interest: Disclosures can be found alongside this article at openres.ersjournals.com

Copyright $\odot$ ERS 2017. This article is open access and distributed under the terms of the Creative Commons Attribution Non-Commercial Licence 4.0. 


\section{Introduction}

Pulmonary fibrosis is a respiratory disease characterised by scarring of the lungs, resulting in reduced oxygen transport [1]. Different forms of pulmonary fibrosis exist, with different disease courses and prognosis; however, in the majority of patients the disease is progressive. The main symptoms experienced by patients are cough, fatigue and breathlessness [2]. Pulmonary fibrosis impacts the social and emotional wellbeing of patients, partners and other family caregivers, in addition to its physical impact [3-6].

In recent years, several studies have been conducted to generate more information on the needs of patients with pulmonary fibrosis, especially in idiopathic pulmonary fibrosis (IPF) [3-11]. However, the needs of partners often remain unnoticed. Previous studies show the need for better disease related education, earlier diagnosis, support groups and better access to specialist centres and interstitial lung disease (ILD) specialist nurses. One of the crucial factors that empower patients to play a more active role in their care is education. However, the best way of educating pulmonary fibrosis patients and their partners needs to be established.

A pulmonary fibrosis patient information meeting is organised annually in the Erasmus University Medical Center (Rotterdam, the Netherlands) and at the Thoraxklinik (Heidelberg, Germany) to provide additional information about pulmonary fibrosis. During these meetings we use an interactive voting system, which enables us to gather information about participants' disease experiences and learn from their perspectives and preferences in care. These findings can be used to improve care for patients with fibrosis and their partners.

An interactive voting system, in addition, creates an environment where patients and partners can learn from each other's experiences. Outcomes of surveys are not always shared with patients. However, information on problems that patients and partners encounter could be very informative and might generate a feeling of relief, as people learn that others are facing the same difficulties.

Studies on cultural differences in preferences and perspectives in care are limited in pulmonary fibrosis patients $[9,12]$. By using the same survey at the pulmonary fibrosis patient information meetings in the Netherlands and in Germany, we could learn more about possible cultural differences.

The purpose of our study was to determine pulmonary fibrosis patients' and their partners' perspectives and preferences in care. In addition, we studied whether directly projecting survey answers, via an interactive voting system, is informative and wanted by pulmonary fibrosis patients and their partners. We also studied whether cultural differences exist in care needs between pulmonary fibrosis patients and their partners from the Netherlands and Germany.

\section{Methods}

Patients and partners were interviewed during pulmonary fibrosis information meetings at two tertiary ILD centres: the Erasmus University Medical Center and the Thoraxklinik, Heidelberg University Hospital. The three information meetings in the Netherlands took place in 2013, 2014 and 2015 and the meeting in Germany in 2014. The content of the programme is shown in online supplementary table S1. We use the terminology "partners", but this term also includes other family members or nearest and dearest when applicable. We avoided the word caregiver, as we think that a relationship between patient and partner (or other nearest and dearest) comprises more than caregiving alone. In the Netherlands, patients and partners answered questions anonymously via interactive voting boxes (TurningPoint 2008; Keepad Interactive, Sydney, Australia). The questions were projected on a wide screen. Questions and answers were first read aloud, then a clock countdown of $10 \mathrm{~s}$ was started. The system recorded the number of votes and results were projected directly. In Germany, questionnaires were handed out to all participants and questions were discussed afterwards. Questions were derived by literature search and input of patients, ILD physicians, ILD specialist nurses an ILD research nurse. The Generalised Anxiety Disorder-single item (GAD-SI) questionnaire was administered before the lectures started, to avoid the influence of information presented during the meeting [13]. We asked participants 37 questions. In this article we present a selection of the questions asked. An overview of all questions is presented in online supplementary table S2.

Permission to use the data was obtained beforehand. All procedures followed were in accordance with the ethical standards of the responsible committee on human experimentation (institutional and national) and with the Helsinki Declaration of 1964, as revised in 2013. Patient permissions for data collection and usage were granted according to specific local requirements of the medical ethical committee at each participating centre. Data were collected and analysed using Microsoft Excel 2010 (Redmond, WA, USA). All data are presented as $\%(\mathrm{n})$, as the number of responders could vary per question.

\section{Results}

278 patients and their partners participated in the Netherlands and 51 in Germany. Demographics are shown in table 1. 


\section{TABLE 1 Demographics of patients and partners}

The Netherlands $(2013+2014+2015)$

Germany (2014)

$\begin{array}{lcc}\text { Patients } & 134(48) & 27(53) \\ \text { Partners } & 144(52) & 24(47) \\ \text { Diagnoses } & \\ \quad \text { IPF } & 88(70) & 20(80) \\ \text { CTD-PF } & 14(11) & 2(8) \\ \text { Exposure related } & 14(11) & 3(12) \\ \text { Unknown } & 10(8) & 0(0)\end{array}$

Data are presented as $\mathrm{n}$ (\%). IPF: idiopathic pulmonary fibrosis; CTD-PF: connective tissue diseaseassociated pulmonary fibrosis. " : based on survey question.

In Germany, $17 \%$ (8) of patients and partners attended the pulmonary fibrosis information meeting the previous year. In the Netherlands, 24\% (15) in 2014 and 18\% (10) in 2015 had attended the previous meeting.

Figure 1 shows that approximately two-thirds of patients and partners experience anxiety as assessed by the validated GAD-SI [13]. The vast majority of participants had experienced misunderstanding because people do not know what pulmonary fibrosis is (figure 2). Patients in the Netherlands prefer to talk about matters concerning the end of life early in the course of the disease, while in Germany this is less explicit (figure 3). In all groups, there is great need for information on the disease (figure 4).

Other questions revealed that $88 \%$ (21) of German and 61\% (38) of Dutch partners would like to have more care for partners. Psychological support was wanted by more than half of the German partners $(55 \%, n=12)$. In addition, the majority of patients in the Netherlands and Germany would appreciate the possibility of psychological support: $80 \%$ (107) and 79\% (19), respectively. $23 \%$ (21) of patients think that psychological support is lacking in current care.

In the Netherlands, patient and partner priorities in care are information on their disease $(47 \%, \mathrm{n}=62)$; access to an expertise centre $(27 \%, n=35)$; and practical support $(18 \%, n=23)$. Many Dutch patients desire treatment and follow-up in a hospital with the most expertise $(58 \%, \mathrm{n}=67)$, but a third of the patients $(30 \%, n=34)$ prefer shared care between the expertise centre and a pulmonologist nearby. In Germany, the same percentage of patients favour shared care between the expertise centre and a pulmonologist nearby $(29 \%, n=7)$, while only a third of patients prefer treatment only at an expertise centre $(33 \%, n=8)$. Additionally, a minority $(17 \%, n=4)$ of German patients prefer a combination of care by their general practitioner and pulmonologist nearby, whereas in the Netherlands only 4\% (5) of patients prefer this option. Specialised centres offer access to clinical trials. Many patients desire active involvement in the development of clinical trials: $77 \%$ (20) of German and 68\% (77) of Dutch patients.

FIGURE 1 Patients' and partners' experience of anxiety in the Netherlands (NL) and Germany (GE), based on the Generalised Anxiety Disorder-single item questionnaire [13]. Subject responses to the question "How often in the past 2 weeks did you have problems relaxing?"

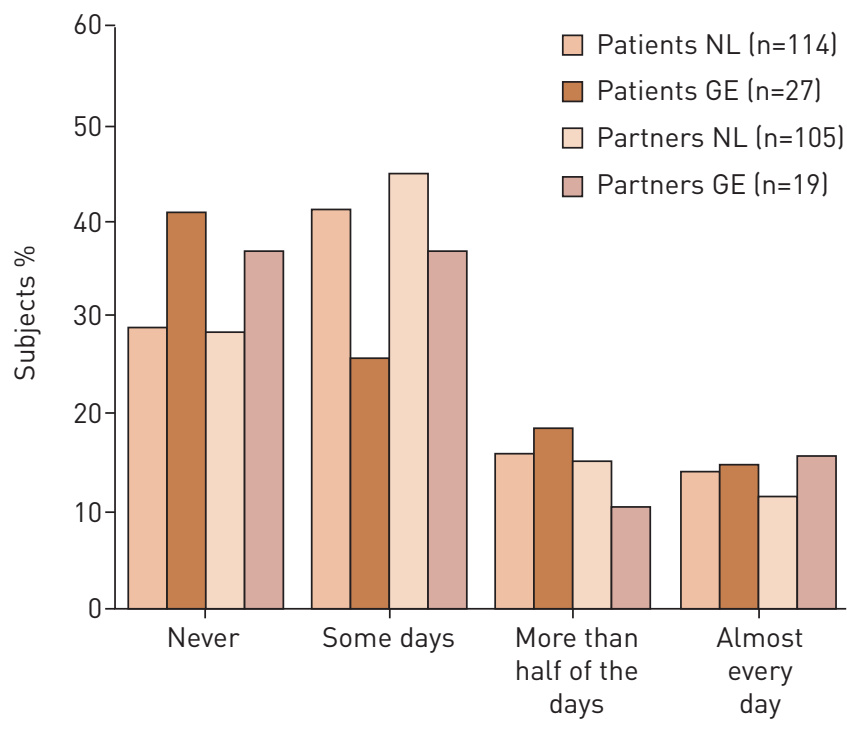




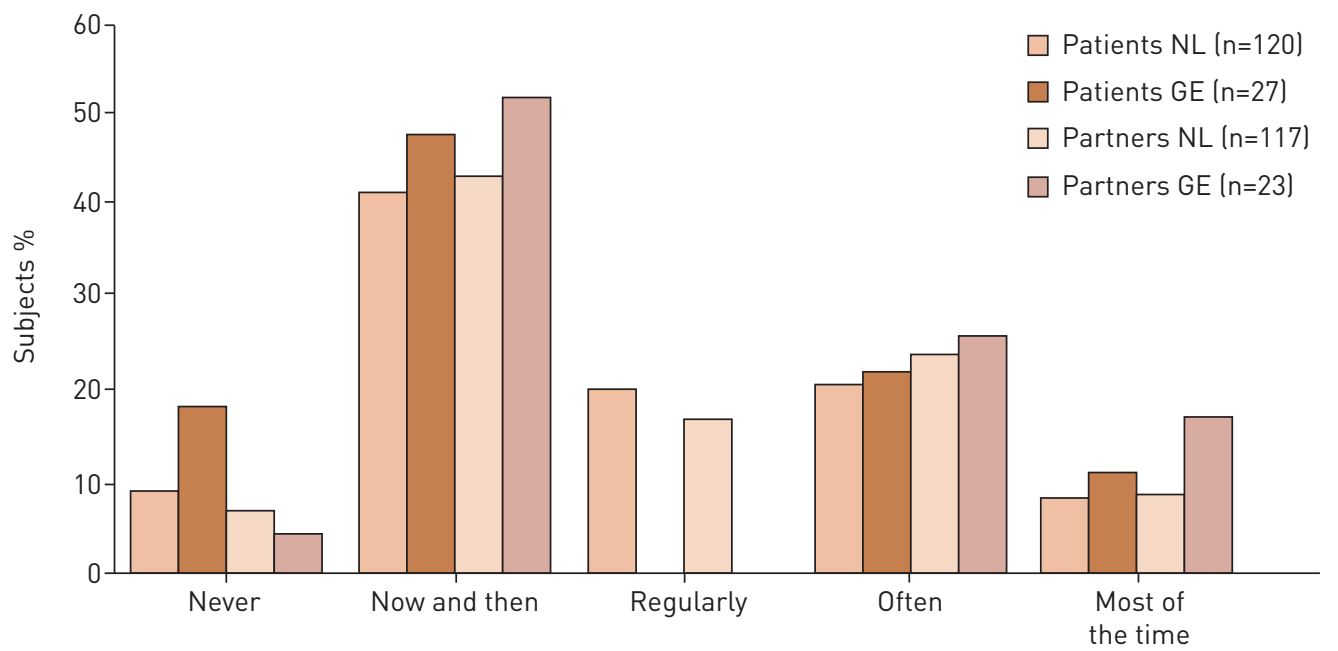

FIGURE 2 Experience of misunderstanding by patients and partners in the Netherlands (NL) and Germany (GE). Subject responses to the question "How often do you feel misunderstood because people do not know what pulmonary fibrosis is?"

At the Erasmus University Medical Center, ILD specialist nurses provide general care. They give additional information about disease, care options, medication and oxygen supply and are easily accessible by phone and email. Most $(88 \%, n=36)$ Dutch patients think seeing an ILD specialist nurse is beneficial. At the time of the survey, there was no ILD specialist nurse in Germany, although 55\% (12) of patients asked for such services. $21 \%$ (30) of patients and partners from both countries would like to see the ILD specialist nurse every time they visit their doctor. However, the majority of patients prefer to see the ILD specialist nurse only when asked for $(67 \%, \mathrm{n}=94)$.

The interactive voting system was well appreciated and considered informative by patients and partners (figure 5). Patients and partners in both countries considered the meetings to be very useful and the majority felt more secure after attending them (figures 6 and 7).

\section{Discussion}

This study improves the current knowledge of the needs of patients with pulmonary fibrosis and their partners. It emphasises the major impact that pulmonary fibrosis has on the emotional wellbeing of patients and partners and the need for better education on all aspects of disease and psychological and practical support. Treatment is preferred in expertise centres with access to ILD specialist nurses, and involvement in the development of clinical trials is wanted. Moreover, this study demonstrates a new way of questioning and educating patients and partners, using an interactive voting system which projected answers directly. Patients and partners found this method pleasant and informative. No major cultural differences existed between the findings in in the Netherlands and Germany.

\section{Anxiety}

In our study, many patients and partners reported some level of anxiety. KReUTER et al. [14] showed that depression and anxiety are common comorbidities in IPF. In another study of 502 IPF patients, anxiety was found in $9.4 \%$ at baseline [15]. This is comparable with the number of patients and partners in our group experiencing anxiety almost every day (11-16\%). Multiple factors could contribute to the high prevalence of anxiety in this population. Anxiety is a known emotional response in breathless patients, but a background of anxiety can also increase the perception of breathlessness [16]. Partners feel helpless because they cannot relieve the breathlessness $[2,17]$. The relationship between breathlessness and anxiety in patients and partners is also seen in chronic obstructive pulmonary disease (COPD) and chronic heart failure $[18,19]$. In COPD, anxiety is one of the comorbidities with the greatest influence on self-reported health status [20]. The progressive nature of the disease, especially in IPF, could also cause anxiety. Furthermore, the coughing attacks suffered by many pulmonary fibrosis patients increases anxiety of partners, as they fear the next attack could be fatal [5]. Additionally, for certain patients, decisions about screening and being on the waiting list for lung transplantation might play a role $[7,21]$.

\section{Misunderstanding}

Patients and their partners both feel misunderstood by society, as people often do not know what pulmonary fibrosis is. This corresponds with the findings of the study of Russell et al. [12], where IPF 
FIGURE 3 Preference of talking about matters concerning the end of life in patients from the Netherlands (NL) and Germany (GE). Responses to the statement "I would prefer to talk about matters concerning end of life at an early stage of my disease".

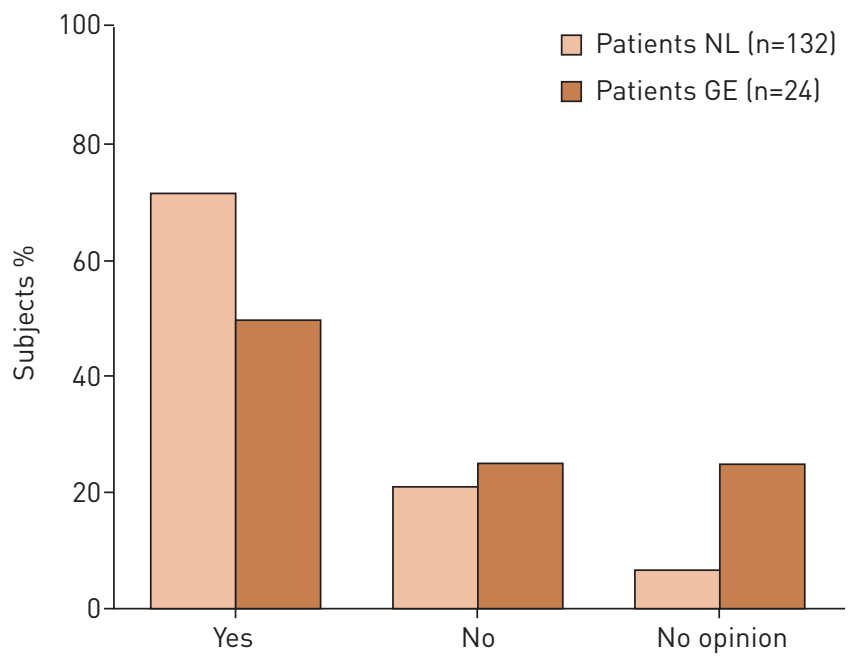

patients report feeling angry and frustrated because society has little knowledge of the disease. Moreover, patients often do not look sick to start with, which makes it difficult for family and friends to understand the devastating impact of the disease, troubling patients to talk about their condition $[2,7]$.

\section{Psychological support}

Many patients and partners in the Netherlands and Germany wish to receive psychological support, consistent with the findings of previous studies $[3,4,9,12]$. The progressive nature of the disease forces patients to adapt to growing restrictions in things they love to do and limits them in the activities of everyday life, impacting not only physical, but also emotional wellbeing. Patients become dependent on their loved ones and relationships with friends and family change [2, 4]. Financial problems can occur when patients have to stop working [22]. Additionally, psychological distress can increase when patients start on supplemental oxygen. Besides loss of independence due to logistical difficulties, oxygen makes the disease more visible [22]. For partners, the disease changes their lives and the relationship as well [17]. They become the main support in patients' lives and often feel they have to be the "strong one", allowing themselves no time to deal with their own grief. The high number of requests for more care and psychological support for partners found in our study illustrates the impact pulmonary fibrosis has on partners and corresponds with previous findings $[4,17]$. In both centres, the survey data helped to improve the level of psychological care and the tailoring of this care to the needs of the patients and partners.

\section{End of life}

The majority of pulmonary fibrosis patients in our study prefer to talk about matters concerning end of life at an early stage of the disease, but cultural differences exist. The study by OvergaARD et al. [5] shows that reactional dyssynchrony can occur in coping with the disease. National Institute for Health and Care

FIGURE 4 Need for information on disease and prospects in patients and partners from the Netherlands (NL) and Germany (GE). Responses to the statement "I would like to know everything about my disease and its prospects".

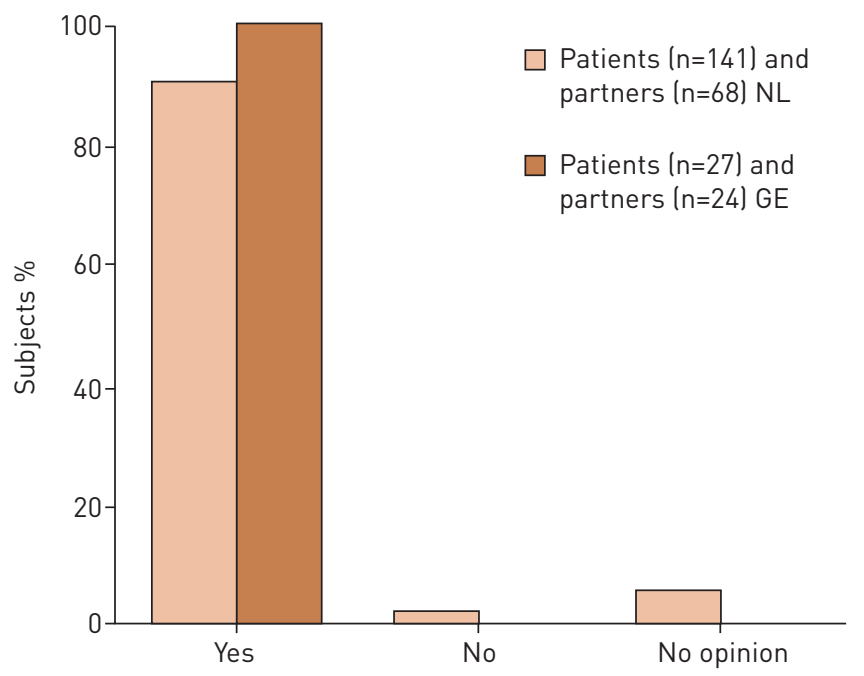


I find seeing the response of the other participants...
Do you find it informative to see the answers of the other participants on the screen?
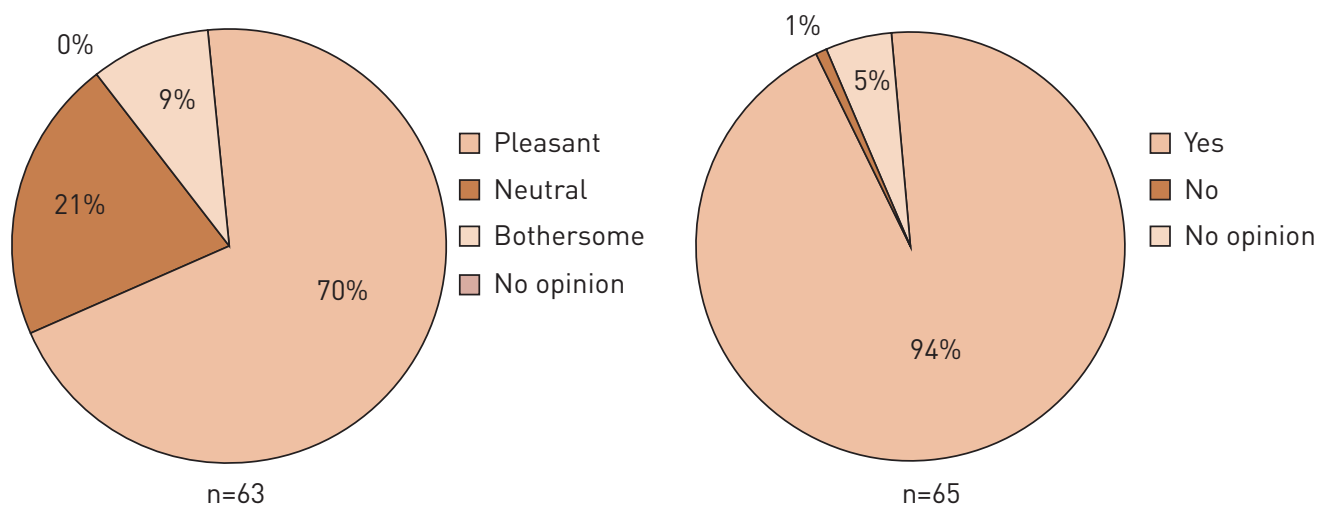

FIGURE 5 Feedback on interactive voting system in the Netherlands.

Excellence (NICE) guidelines on IPF state that discussion about end-of-life issues should start at diagnosis, and prior studies show patients' need for information on end-of-life issues [23-25]. In addition, the American Thoracic Society recommends advanced care planning for patients with severe lung disease [26]. However, it must be realised that these conversations could be distressing to patients and partners [27]. As mentioned by Тніскетт et al. [8], it is important to talk about disease progression and management so patients can prepare for the future, but this process should be personalised and develop over time. This corresponds with the wishes of patients and partners to receive paced information on disease and being able to plan care in advance [5].

\section{Education}

Patients and partners have a consistent wish to receive more information on the disease and its prospects [3, 12, 25, 27-29]. Patients often consult the internet, but information found is frequently incomplete, inaccurate and not up to date [11]. Although the need for information is well known in pulmonary fibrosis, studies to improve education and care are scarce [27]. Lindell et al. [27] studied whether a 6-week disease-management programme would improve disease symptoms and health-related quality of life (HRQoL) in patients with IPF. Strikingly, patients' anxiety and HRQoL scores deteriorated, while the stress levels of partners improved. Post-intervention interviews showed that the course was perceived to be beneficial by all participants. In the current study, we used an interactive voting system with direct projection to improve patients' and partners' knowledge of the disease. Although this method cannot be compared to a disease-management programme, we found that after the meeting most patients felt more secure. The majority of participants found the interactive voting system pleasant and informative. Studies on using interactive response systems in teaching have been shown to improve learning, cognitive performance and student test scores [30-32]. This method could therefore not only be a good and efficient way to inform patients and partners, but also enhance the information patients and partners can absorb.

FIGURE 6 Perception of patients and partners from the Netherlands (NL) and Germany (GE) of the usefulness of the information meeting.

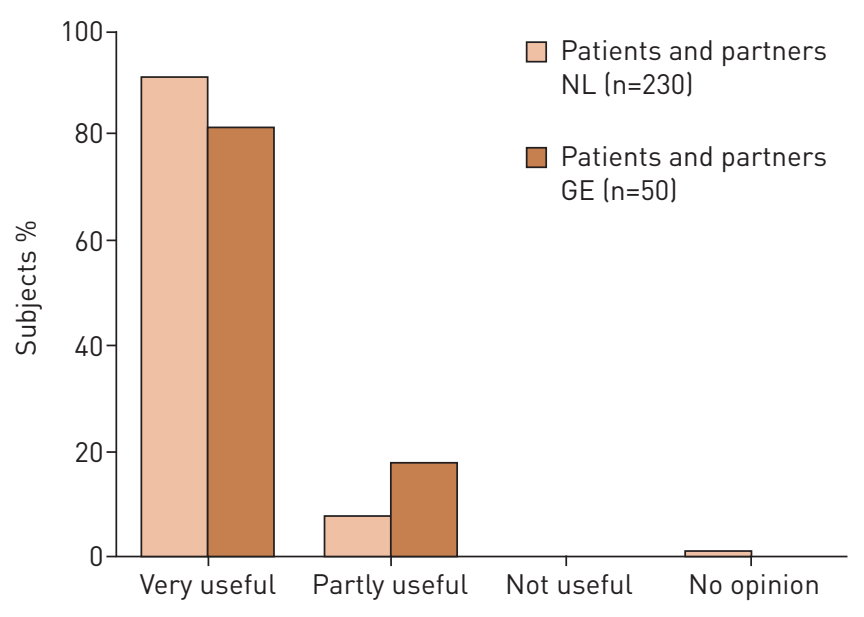


FIGURE 7 General feeling of patients and partners from the Netherlands (NL) and Germany (GE) after the information meeting.

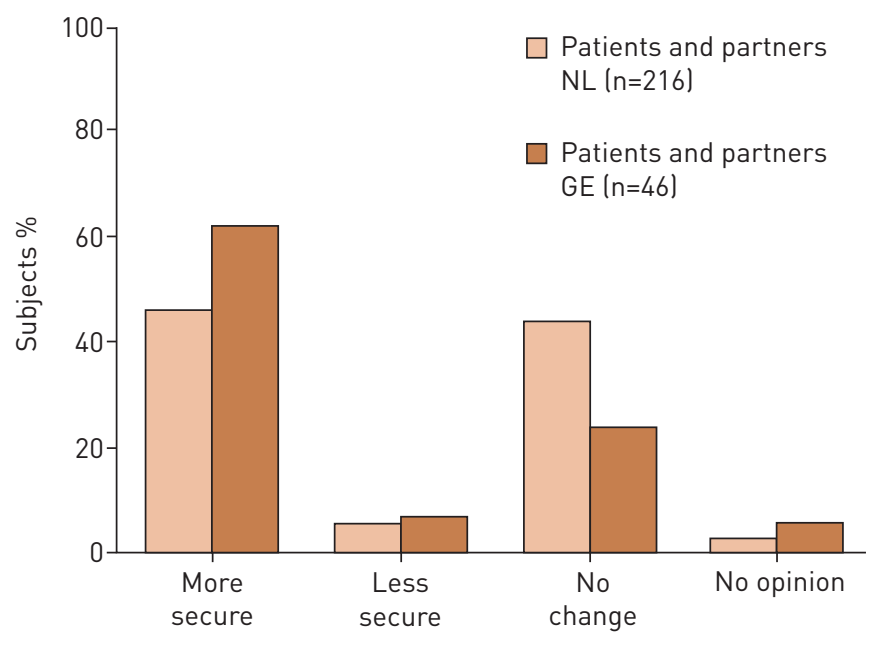

\section{Expertise centres}

The majority of Dutch patients in this study wished to be treated and followed-up in a centre of expertise. This result could be biased, because the pulmonary fibrosis information meetings were held in expertise centers; however, similar findings were reported by Schoenheit et al. [3]. They found that patients treated in expertise centres were more satisfied on disease information and quality of care. Yet the German patients in the present study preferred a combination of treatment and follow-up at an expertise centre and pulmonologist nearby in equal numbers those preferring treatment at an expertise centre only. Geographical reasons may explain this difference, as in the Netherlands an expertise centre is usually within $<2 \mathrm{~h}$ range due to the small size of the country. The British Lung Foundation states that a considerable amount of ongoing care must be available and provided at local hospitals. The current study underlines the importance of this, as patients should be given the option of shared care, although in some countries reimbursement rules may unfortunately complicate such collaborative care options.

\section{Research}

In expertise centres, patients generally get more access to information about and enrolment in clinical trials. According to the British Lung Foundation, only $42 \%$ of patients currently receive information on clinical trials [33]. A study of diabetic patients attending an ongoing trial shows that attending clinical trials improves quality of care, patient interest and engagement in their overall health services and reduces healthcare costs [34]. Moreover, patients were more motivated, informed and aware of their disease and how to deal with their condition. Our study shows that patients not only want to receive information about and participate in clinical trials, but also wish to be involved in the development of trials. Involvement of patients in designing clinical trials could not only help identifying which outcomes are most relevant to patients, but could also improve feasibility and patient participation in trials and tailored dissemination of outcomes [12, 35].

\section{ILD specialist nurses}

ILD specialist nurses manage symptoms, treatment and possible side-effects, coordinate care and involve other healthcare services where necessary. They also teach patients how to cope with their disease and create a comfortable environment were patients can discuss their fears and problems [7, 8, 29]. In the Netherlands, most patients find access to an ILD specialist nurse beneficial. The NICE guideline states that all patients and their partners should have access to an ILD specialist nurse in all phases of the care pathway [23]. Yet, currently, as seen in Germany, not all pulmonary fibrosis patients have access to ILD specialist nurses, although the demand for such services is high [12,33]. We agree with the NICE guidelines that all patients and their partners should have access to ILD specialist nurses. However, appointments with ILD specialist nurses should be individually tailored, as our study shows that patients and partners prefer to see the ILD specialist nurse only when required.

\section{Cultural differences}

We found no major cultural differences between Germany and the Netherlands. This in line with previous studies, showing that the emotional impact of disease is similar in different countries $[9,12,28]$. Practical care preferences might vary due to differences in the organisation of care, geography, reimbursement 
criteria and local habits $[9,12,27,36]$. Cultural differences should be taken into consideration when trying to optimise guidelines for care.

\section{Limitations}

The interactive voting system used in the current study carries some limitations. Patients can potentially respond to questions aimed at partners and vice versa, resulting in higher numbers of answers and biased scores. In addition, participants might have responded too late or chosen not to respond, and a few participants left during the meeting for various reasons (fatigue, transport and unknown reasons), resulting in missing data. We therefore report in our results the absolute numbers of responders as well as percentages. Furthermore, patients and partners attending the pulmonary fibrosis information meeting in the Netherlands could have attend previous meetings. However, we found that only $24 \%$ in 2014 and $18 \%$ in 2015 had attended the information meeting the previous year, indicating only a small overlap in the data. As the total number of participants (278 in the Netherlands and 51 in Germany) is high compared to other studies assessing preferences of pulmonary fibrosis patients and their partners $[3-5,12,17]$, this probably dilutes the potential voting errors and overlap in data. In the current study, questions were generated by healthcare providers of different backgrounds and patients. Although these questions were not validated (except for the GAD-SI), they were considered to be informative and useful by the participants and were used by the centres to improve care.

\section{Conclusion}

This study in a large cohort of patients with pulmonary fibrosis and their partners confirms the major impact of pulmonary fibrosis on emotional wellbeing and improves current knowledge of their needs. There is need for better education on all aspects of disease, psychological and practical support and the need for ILD specialist nurses. No major cultural differences were found between Germany and the Netherlands. The method of interactively educating and interviewing could be a good and efficient way to generate new insights into pulmonary fibrosis care and is informative for patients and their partners. However, further research into the best method of education and on tailored support programmes is needed, as these are essential to improve care for pulmonary fibrosis patients and their partners.

\section{References}

1 Travis WD, Costabel U, Hansell DM, et al. An official American Thoracic Society/European Respiratory Society statement: update of the international multidisciplinary classification of the idiopathic interstitial pneumonias. $A m$ J Respir Crit Care Med 2013; 188: 733-748.

2 Center for Drug Evaluation and Research (CDER), U.S. Food and Drug Administration (FDA). The Voice of the Patient; A series of reports from the U.S. Food and Drug Administration's (FDA's) Patient-Focused Drug Development Initiative. Idiopathic Pulmonary Fibrosis. March 2015. www.fda.gov/downloads/ForIndustry/ UserFees/PrescriptionDrugUserFee/UCM440829.pdf Date last updated: March 2015.

3 Schoenheit G, Becattelli I, Cohen AH. Living with idiopathic pulmonary fibrosis: an in-depth qualitative survey of European patients. Chron Respir Dis 2011; 8: 225-231.

4 Bajwah S, Higginson IJ, Ross JR, et al. The palliative care needs for fibrotic interstitial lung disease: a qualitative study of patients, informal caregivers and health professionals. Palliat Med 2013; 27: 869-876.

5 Overgaard D, Kaldan G, Marsaa K, et al. The lived experience with idiopathic pulmonary fibrosis: a qualitative study. Eur Respir J 2016; 47: 1472-1480.

6 Sampson C, Gill BH, Harrison NK, et al. The care needs of patients with idiopathic pulmonary fibrosis and their carers (CaNoPy): results of a qualitative study. BMC Pulm Med 2015; 15: 155.

7 Duck A, Spencer LG, Bailey S, et al. Perceptions, experiences and needs of patients with idiopathic pulmonary fibrosis. J Adv Nurs 2015; 71: 1055-1065.

8 Thickett DR, Kendall C, Spencer LG, et al. Improving care for patients with idiopathic pulmonary fibrosis (IPF) in the UK: a round table discussion. Thorax 2014; 69: 1136-1140.

9 Bonella F, Wijsenbeek M, Molina-Molina M, et al. European IPF Patient Charter: unmet needs and a call to action for healthcare policymakers. Eur Respir J 2016; 47: 597-606.

10 Yount SE, Beaumont JL, Chen SY, et al. Health-related quality of life in patients with idiopathic pulmonary fibrosis. Lung 2016; 194: 227-234.

11 Fisher JH, O'Connor D, Flexman AM, et al. Accuracy and reliability of internet resources for information on idiopathic pulmonary fibrosis. Am J Respir Crit Care Med 2016; 194: 218-225.

12 Russell AM, Ripamonti E, Vancheri C. Qualitative European survey of patients with idiopathic pulmonary fibrosis patients' perspectives of the disease and treatment. BMC Pulm Med 2016; 16: 10.

13 Donker T, van Straten A, Marks I, et al. Quick and easy self-rating of Generalized Anxiety Disorder: validity of the Dutch web-based GAD-7, GAD-2 and GAD-SI. Psychiatry Res 2011; 188: 58-64.

14 Kreuter M, Ehlers-Tenenbaum S, Palmowski K, et al. Impact of comorbidities on mortality in patients with idiopathic pulmonary fibrosis. PLoS One 2016; 11: e0151425.

15 Behr J, Kreuter M, Hoeper MM, et al. Management of patients with idiopathic pulmonary fibrosis in clinical practice: the INSIGHTS-IPF registry. Eur Respir J 2015; 46: 186-196.

16 Janssen DJ, Wouters EF, Spruit MA. Psychosocial consequences of living with breathlessness due to advanced disease. Curr Opin Support Palliat Care 2015; 9: 232-237.

17 Belkin A, Albright K, Swigris JJ. A qualitative study of informal caregivers' perspectives on the effects of idiopathic pulmonary fibrosis. BMJ Open Respir Res 2014; 1: e000007. 
18 Janssen DJ, Spruit MA, Uszko-Lencer NH, et al. Symptoms, comorbidities, and health care in advanced chronic obstructive pulmonary disease or chronic heart failure. J Palliat Med 2011; 14: 735-743.

19 Jácome C, Figueiredo D, Gabriel R, et al. Predicting anxiety and depression among family carers of people with chronic obstructive pulmonary disease. Int Psychogeriatr 2014; 26: 1191-1199.

20 Frei A, Muggensturm P, Putcha N, et al. Five comorbidities reflected the health status in patients with chronic obstructive pulmonary disease: the newly developed COMCOLD index. J Clin Epidemiol 2014; 67: 904-911.

21 Vermeulen KM, Bosma OH, Bij W, et al. Stress, psychological distress, and coping in patients on the waiting list for lung transplantation: an exploratory study. Transpl Int 2005; 18: 954-959.

22 Wuyts WA, Peccatori FA, Russell AM. Patient-centred management in idiopathic pulmonary fibrosis: similar themes in three communication models. Eur Respir Rev 2014; 23: 231-238.

23 National Institute for Health and Care Excellence (NICE). Diagnosis and Management of Suspected Idiopathic Pulmonary Fibrosis. www.nice.org.uk/guidance/cg163/evidence/full-guideline-190086877 Date last updated: June 2013.

24 Bridges JF, Paly VF, Barker E, et al. Identifying the benefits and risks of emerging treatments for idiopathic pulmonary fibrosis: a qualitative study. Patient 2015; 8: 85-92.

25 Bajwah S, Koffman J, Higginson IJ, et al. 'I wish I knew more ...' the end-of-life planning and information needs for end-stage fibrotic interstitial lung disease: views of patients, carers and health professionals. BMJ Support Palliat Care 2013; 3: 84-90.

26 Lanken PN, Terry PB, Delisser HM, et al. An official American Thoracic Society clinical policy statement: palliative care for patients with respiratory diseases and critical illnesses. Am J Respir Crit Care Med 2008; 177: 912-927.

27 Lindell KO, Olshansky E, Song MK, et al. Impact of a disease-management program on symptom burden and health-related quality of life in patients with idiopathic pulmonary fibrosis and their care partners. Heart Lung 2010; 39: 304-313.

28 Collard HR, Tino G, Noble PW, et al. Patient experiences with pulmonary fibrosis. Respir Med 2007; 101: $1350-1354$.

29 Duck A, Pigram L, Errhalt P, et al. IPF Care: a support program for patients with idiopathic pulmonary fibrosis treated with pirfenidone in Europe. Adv Ther 2015; 32: 87-107.

30 Wenz HJ, Zupanic $\mathrm{M}$, Klosa $\mathrm{K}$, et al. Using an audience response system to improve learning success in practical skills training courses in dental studies - a randomised, controlled cross-over study. Eur J Dent Educ 2014; 18: 147-153.

31 Uhari M, Renko M, Soini H. Experiences of using an interactive audience response system in lectures. BMC Med Educ 2003; 3: 12 .

32 Datta R, Datta K, Venkatesh MD. Evaluation of interactive teaching for undergraduate medical students using a classroom interactive response system in India. Med J Armed Forces India 2015; 71: 239-245.

33 British Lung Foundation. Lost in the System. IPF: the Patient Experience in England. www.blf.org.uk/sites/default/files/ BLF-IPF-Report-2015-Lost-in-the-System-250215.pdf Date last accessed: February 23, 2016. Date last updated: 2015.

34 Shen J, Buechler A, Byrne J, et al. Clinical Research Participation as a Care Option. www.quintiles.com/library/ white-papers/clinical-research-participation-as-a-care-option Date last accessed: February 24, 2016. Date last updated: October 28, 2015.

35 Patient-Centered Outcomes Research Institute. About us. www.pcori.org/about-us Date last accessed: April 1, 2016. Date last updated: October 6, 2014

36 Wijsenbeek M, Bendstrup E, Ross J, et al. Cultural differences in palliative care in patients with idiopathic pulmonary fibrosis. Chest 2015; 148: e56. 